\title{
Synthesis and thermal stability of $\mathrm{Pt}_{3} \mathrm{Si}, \mathrm{Pt}_{2} \mathrm{Si}$, and PtSi films grown by e-beam co-evaporation
}

Robert T. Fryer ${ }^{\mathrm{a}}$, Robert J. $\underline{\operatorname{Lad}}^{\mathrm{b}}$

a Corresponding author (all stages of pre- and post-publication)

Email: robert.fryer@maine.edu

Department of Physics \& Astronomy and Laboratory for Surface Science \&

Technology, University of Maine, Orono, ME 04469-5708, U.S.A.

b Email: rilad@maine.edu

Department of Physics \& Astronomy and Laboratory for Surface Science \& Technology, University of Maine, Orono, ME 04469-5708, U.S.A.

\section{Abstract}

Platinum silicide thin films formed via solid-solid reaction of Pt-Si interfaces play an important role as interconnects in microelectronics. This "self-aligned" silicide formation, however, is diffusion-limited and only $\mathrm{Pt}_{2} \mathrm{Si}$ and $\mathrm{PtSi}$ phases form. Also, their usefulness in electronic applications at high temperatures is limited due to agglomeration effects. Here, e-beam co-evaporation is presented as a means of fabricating well-defined films of $\mathrm{Pt}_{3} \mathrm{Si}$ as well as the $\mathrm{Pt}_{2} \mathrm{Si}$ and $\mathrm{PtSi}$ phases familiar to conventional, self-aligned silicide technology. Pt-Si films with a range of compositions (silicon atomic fractions of $X_{\mathrm{Si}}=0.00-0.77$ ) were grown on r-sapphire substrates by co-deposition of independently controlled Pt and $\mathrm{Si}$ evaporant fluxes at $400^{\circ} \mathrm{C}$. Phase, morphology, and electronic properties were analyzed upon deposition and after vacuum annealing for $48 \mathrm{~h}$ at $1000^{\circ} \mathrm{C}$. As-deposited films with $X_{\mathrm{Si}}<0.70$ are polycrystalline and at higher $\mathrm{Si}$ concentrations are fully amorphous. Valence spectra from $\mathrm{Pt}, \mathrm{Pt}_{2} \mathrm{Si}$, and $\mathrm{PtSi}$ films confirm previous reports and a valence spectrum is presented for the stoichiometric $\mathrm{Pt}_{3} \mathrm{Si}$ phase; these data provide experimental support for 
recently proposed revisions to the standard transition metal-silicon bonding model. Asdeposited films, nominally $200 \mathrm{~nm}$ thick, are electrically conductive in the range 0.1 $4.0 \times 10^{6} \mathrm{~S} / \mathrm{m}$ and remain so after vacuum annealing for $48 \mathrm{~h}$ at $1000{ }^{\circ} \mathrm{C}$. The phase, morphological, and electrical stabilities are attributed to the finely grained as-deposited morphologies of co-evaporated Pt silicide films, which hinder agglomeration at $1000^{\circ} \mathrm{C}$ for much greater times than do morphologies of traditional, self-aligned silicides grown via solid-state reaction.

Keywords: electrode materials, vapour deposition, thin films, transition metal alloys and compounds, thermal analysis, X-ray and UV spectroscopies

\section{Introduction}

Solid-state reacted transition metal silicides serve many critical roles in silicon-based microelectronics (e.g., as interconnects) but the continued miniaturization of integrated circuits (ICs) puts many new demands on silicide materials. The interesting properties of PtSi include an exceptionally low Schottky barrier height on $p$-type Si $(0.28 \mathrm{eV})$ [1], and although its electrical conductivity is only about half that of the more common $\mathrm{TiSi}_{2}$ [2], the film conductivity is preserved at linewidths as narrow as $0.15 \mu \mathrm{m}$, while that of $\mathrm{TiSi}_{2}$ critically diminishes below $0.50 \mu \mathrm{m}[3,4]$. Furthermore, Pt silicides have a relatively robust thermal and chemical stability [5] and low formation temperatures [6], which make them attractive for next-generation devices, given the high temperatures found in the final stages of some device fabrication processes [2]. With continued interest in Pt-Si materials, 
multiple recent revisions have been made to the Pt-Si binary phase diagram [7-11] and to the electronic structure and bonding models of the PtSi and $\mathrm{Pt}_{2} \mathrm{Si}$ phases [12-17].

The ability to grow silicide films with well-defined metal-Si stoichiometry across the entire compositional range is an attractive feature of the e-beam co-deposition technique and it has many advantages over other silicide growth methods. Firstly, device miniaturization requires very shallow contact depths and it is widely recognized that this will not be achieved by traditional solid-state reacted, "self-aligned" techniques. Co-deposition of metal and Si has been suggested as a means of minimizing the consumption of substrate $\mathrm{Si}$ during metal silicide formation (silicidation), and this approach has been demonstrated for co-evaporated Pt silicides in a series of experiments by Eizenberg and Tu [18-20], in which Pt-Si films with $X_{\mathrm{Si}}$ ranging from 0.25 to 0.50 were co-deposited on $n$-type $\mathrm{Si}$ and annealed; the results indicated that contact depth can be directly controlled via deposited film compositions. Secondly, the tunability of film composition affords the deposition of Si-rich (off-stoichiometric) films in which the excess Si offers a safety margin during thermal oxidation, as has been demonstrated for co-sputtered Pt-Si thin films by Murarka et al. [21]. Finally, by co-depositing films with appropriate metal-to-Si ratios, crystalline phases that do not form during self-aligned silicide growth can be targeted; as is characteristic of diffusion-limited solid-state reactions, only a subset of all thermodynamically stable phases can kinetically form throughout the duration of the reaction. For example, only the $\mathrm{Pt}_{2} \mathrm{Si}$ and PtSi phases form during self-aligned platinum silicide film growth [22-24] and other Pt-Si phases (e.g., $\mathrm{Pt}_{3} \mathrm{Si}$ ) develop only as minor phases during growth or subsequent processing [25-27]. Using co-evaporation, the mixing of Pt and Si species occurs locally during deposition, requiring much smaller diffusion lengths to achieve silicide formation. 
Agglomeration (a.k.a. solid-state dewetting) plagues micro and nanoscale applications of thin films at elevated temperatures, where narrow electrode linewidths progress from continuous films to discontinuous island-type structures, thereby diminishing electrically conductive pathways. The thermodynamics of the solid-state dewetting of thin films has been extensively reviewed in Ref. [28] by C.V. Thompson. Film agglomeration is driven by solid-state surface self-diffusion, whereby material is transported away from grain boundaries in order to reduce gradients in the film curvature and minimize the free energy of the film-substrate interface. Grooving at a particular grain boundary will proceed until a sufficiently large hole has formed through the entire thickness of the film, after which capillary energies drive the retraction of its edge, furthering hole growth.

Thermodynamically, however, the greatest groove depth attainable at a particular grain boundary is functionally proportional to the radius of the grains. Hole nucleation is therefore suppressed for grain sizes below some critical grain radius [28]. For this reason, a smooth, finely grained film morphology should aid in the suppression of agglomeration; the high density of grain boundaries delays the rate of coarsening, which thereby limits grain boundary grooving and long-range material diffusion, and ultimately hinders agglomeration. Physical vapor co-deposited films generally have smoother surfaces and are more finely grained than films formed by solid-state reaction [29]. Thus, growth by electron beam co-evaporation is proposed as an approach to suppress agglomeration effects in Pt-Si thin films. Indeed, these films are shown herein to be morphologically stable at temperatures up to $1000^{\circ} \mathrm{C}$ and for vacuum annealing times well beyond where solidstate reacted Pt silicides routinely agglomerate [21].

\section{Experimental}


Pt-Si thin films with various compositions $\left(X_{\mathrm{Si}}=0.00\right.$ to 0.77$)$ were grown on epitaxially polished r-sapphire substrates at $400^{\circ} \mathrm{C}$ by electron beam (e-beam) co-evaporation from independently controlled high purity Pt (99.99995\%) and Si (99.999\%) sources. Blanket film coverage of $200 \mathrm{~nm}$ thick Pt-Si samples were grown in a UHV deposition chamber with a base pressure $<7 \times 10^{-8} \mathrm{~Pa}$. Both evaporant fluxes were individually measured by quartz crystal monitors (QCMs) that were calibrated against film heights measured by surface profilometry. The evaporant fluxes both impinged at a $28^{\circ}$-angle relative to the sample normal and onto the centrally located sample holder (ca. $40 \mathrm{~cm}$ from the sources), which rotated at $0.1 \mathrm{~Hz}$ while heating the substrates at $400{ }^{\circ} \mathrm{C}$. Following film deposition, samples were transferred in vacuo to an X-ray photoelectron spectroscopy (XPS) chamber for corelevel (CL) and valence band (VB) analysis, measured at room-temperature using $\mathrm{Al} \mathrm{K \alpha}$ radiation and a SPECS hemispherical electron analyzer. Binding energy calibration of XPS data is accurate to $\pm 0.1 \mathrm{eV}$ following a Fermi edge fitting procedure in the SpecsLab data acquisition software and corroboration with a sputter cleaned Au thin film.

The films were characterized in the as-deposited state as well as after various vacuum annealing times. Annealing of the films was performed using a graphite/PBN heater for up to $48 \mathrm{~h}$ at $1000^{\circ} \mathrm{C}$ with a $<10^{-6} \mathrm{~Pa}$ background pressure in the UHV chamber. Film electrical conductivities were measured at room-temperature using a 4-point collinear probe and corrected according to film dimension ratios [30]; stylus profilometry was used to measure as-deposited film thicknesses. Room-temperature XRD spectra were acquired with a PANalytical X'Pert Pro Materials Research Diffractometer, using Cu K $\alpha$ radiation and line-focused single-bounce-mirror incident optics; $\theta-2 \theta$ scans were taken with a $3^{\circ}$ offset in $\omega$ to avoid the very intense $\{10 \overline{1} 2\}$ Bragg peaks from the r-sapphire substrate. A Zeiss 
NVision 40 scanning electron microscope (SEM) was used in both secondary and backscattered electron imaging modes for qualitative characterization of the film surface morphologies. Also, energy dispersive X-ray spectroscopy (EDS) was used in tandem with SEM to characterize the elemental composition of select film features.

\section{Results and Discussion}

\subsection{Composition and bonding}

When comparing the silicon fraction of the Pt-Si evaporant flux $\left(\varnothing_{\mathrm{Si}}\right)$ as measured by the QCM with the compositional [atomic] silicon fraction $\left(X_{\mathrm{Si}}\right)$ of the correspondingly deposited film as determined by XPS, it was found that $X_{\mathrm{Si}} \simeq \emptyset_{\mathrm{Si}}$, meaning that there exists a 1:1 sticking coefficient of Pt and Si fluxes on the r-cut sapphire substrate at $400^{\circ} \mathrm{C}$. Film compositions were quantified in vacuo after growth by analyzing XPS core-level intensities before the films were exposed to air. Due to the overlap of the Si $2 p$ photopeaks with the strong Pt $4 f$ plasmon-loss features, the Si $2 s$ was used for quantifications. Whereas simple area integration above background is sufficient for the $\mathrm{Si} 2 \mathrm{~s}$ photopeak, quantification of $\mathrm{Pt}$ requires fitting the data with theoretically modeled synthetic peaks.

Figure 1 displays an XPS spectrum from an as-deposited Pt silicide film with $X_{\mathrm{Si}}=0.31$. The inset plot contains a survey scan over the binding energy (BE) range that includes the $\mathrm{Pt}$ and Si photopeaks used for quantification, while the feature plot is a higher resolution narrow scan of the Pt $4 f / 5 p$ region. The large photoionization cross-sections for the Pt $4 f$ photopeaks (Relative Sensitivity Factors of 9.81 for Pt $4 f_{7 / 2}$ and 1.04 for Si $2 s$ with Al Ka radiation [31]) results in prominent $\mathrm{Pt} 4 f$ satellites arising from $\mathrm{K} \alpha_{3,4}$ radiation in the $\mathrm{Al} \mathrm{X}$ ray source [32], which partly overlap the $4 f_{7 / 2}$ photopeak. Moreover, the Pt $5 p_{1 / 2}$ lies 
between the $4 f$ photopeak doublet and the ensemble of $4 f$ satellites. Thus, the fitting of the Pt $5 p_{1 / 2}$ peak was modeled after the more accessible $5 p_{3 / 2}$ peak. For Pt-Si films, the asymmetry of the Pt photopeaks (and their satellites) (Fig. 1) is characteristic of the Doniach-Sunjic lineshape that is typical in photoemission spectra from metals, and it is increasingly intense with increasing metallic character $[\mathbf{3 3 , 3 4}]$. Thus, to fit Pt photopeak areas for a diverse set of Pt:Si compositions, a tunably asymmetric Lorentzian lineshape [35] was used.

As shown in $\underline{\text { Fig. } 2}$, the BE of the observed Pt $4 f_{7 / 2}$ photopeak increases as the Si fraction, $X_{\mathrm{Si}}$, increases from zero. For a film with $X_{\mathrm{Si}}>0.50$, the $\mathrm{Pt} 4 f_{7 / 2}$ is chemically shifted by +1.46 eV compared to elemental Pt $\left(X_{\mathrm{Si}}=0.00\right)$. A larger core-level shift for films between $X_{\mathrm{Si}}=$ 0.00 and $X_{S \mathrm{i}}=0.33$ compared to those between $X_{\mathrm{Si}}=0.33$ and $X_{\mathrm{Si}}=0.50$ is consistent with the chemical bonding in PtSi and $\mathrm{Pt}_{2} \mathrm{Si}$ : the former consists of strong covalent Pt-Si bonds whereas the latter is comprised of much weaker covalent bonds and a greater number of Pt-Pt metallic bonds [16]. The Pt $4 f_{7 / 2} \mathrm{BE}$ for $\mathrm{Pt}, \mathrm{Pt}_{3} \mathrm{Si}, \mathrm{Pt}{ }_{2} \mathrm{Si}$, and $\mathrm{PtSi}$ are measured to be $70.9 \mathrm{eV}, 71.5 \mathrm{eV}, 72.1 \mathrm{eV}$, and $72.4 \mathrm{eV}$, respectively. These values for all four compositions are consistent with those reported elsewhere for Pt and the Pt silicides [36-43].

Figure 3 presents XPS valence band (VB) spectra measured from Pt-Si films of different compositions. Each data set was background-normalized in intensity and then vertically offset for comparison. Denoted on the left-hand side of the spectra are crystalline phases determined by XRD and Si atomic fractions quantified by XPS. The VB spectra measured from stoichiometric $\mathrm{Pt}, \mathrm{Pt}_{2} \mathrm{Si}$, and $\mathrm{PtSi}$ films agree well with those reported in the literature 


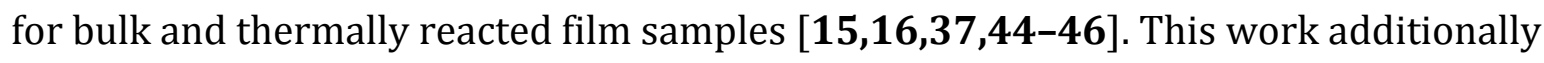
presents a VB-XPS profile from a film consisting of a pure $\mathrm{Pt}_{3} \mathrm{Si}$ phase.

According to the conventional VB model for $d$-metal silicides [37,47-51], the valence structure of Pt silicides has been believed to consist of the following four features: (i) a localized, nonbonding Pt $5 d$ band surrounded by (ii) bonding and (iii) antibonding counterparts of Si 3p-Pt $5 d$ hybridization, and finally, (iv) a high-BE feature that has been observed for every metal silicide and believed to be associated purely with the dehybridized Si $3 s$ states that arise after silicidation disrupts the Si $s p^{3}$ bond. Typical of $d$ metal silicides, the Fermi level intersects the density of $3 p-5 d$ antibonding states. Recently, studies by Franco et al. $[\mathbf{1 5 , 1 6}]$ and Klepeis et al. [14] suggest that the previously accepted model for bonding in the silicides, one of a simple transfer of charge from Si to Pt, where nonbonded Pt $5 d$ orbitals are highly localized and Si $3 s$ orbitals are similarly uninvolved with bonding, is not correct, at least for $\mathrm{Pt}_{2} \mathrm{Si}$ and $\mathrm{PtSi}$. Rather, a more complex bonding picture is proposed, in which a charge reconfiguration creates a mixture of metallic and covalent, 2-centered and 3-centered bonds $[\mathbf{1 2 , 1 4}]$ resulting in a shift of both parent atoms' CLs to higher BEs, relative to their elemental positions. Moreover, in this new model, Pt $5 d$ and Si $3 p$ mixing extends throughout the entire VB, and Si $3 s$, Si $3 d$ and Pt $6 p$ states also contribute, though to a lesser extent, to the bonding in $\mathrm{Pt}_{2} \mathrm{Si}$ and $\mathrm{PtSi}[\mathbf{1 5 , 1 6}]$. Experimental support for this new model is found in Fig. 3 . Three additional, subtle VB features were discovered and labeled by Franco et al. as $\alpha, \beta$, and $\gamma$. These were each identified to be comprised predominantly of Pt $5 d$ states, but with varying contributions from Pt $6 p$, Si 3p, and Si 3s orbitals. All three features were observed by Franco via 
photoelectron and X-ray fluorescence spectroscopies and in local density approximation (LDA) theoretical calculations. The data shown in Fig. $\mathbf{3}$ have revealed subtle features at the $\alpha, \beta$, and $\gamma$ positions in the VB-XPS data for the co-evaporated PtSi phase. When combined with the abovementioned peaks, $i$ through $i v$, these additional features support the notion that the Pt $5 d$ orbitals are not so localized, but rather extend throughout the VB.

The theoretical orbital-resolved partial density of states (PDOS) for PtSi reported by Bentmann et al. [12] is in good agreement with that of Franco et al., including these newly identified features. In addition, Bentmann found that the DOS of $\mathrm{Pt}_{2} \mathrm{Si}$ also possesses an $\alpha$ like feature of similar $d$ and $p$ character, as in PtSi, that is similarly positioned within the VB despite the bulk of the main $d$ manifold shifting towards the Fermi level. This trend can be observed when comparing PtSi to $\mathrm{Pt}_{2} \mathrm{Si}$ in the VB-XPS data of Fig. 3. Whether $\beta$ or $\gamma$ are present in the VB of $\mathrm{Pt}_{2} \mathrm{Si}$ is unclear from Bentmann's calculation, and there is an absence of DOS studies in the literature for the $\mathrm{Pt}_{3} \mathrm{Si}$ phase.

A clear broadening of the VB profile is observed as the Pt content increases, which is consistent with increasing $d-d$ overlap of neighboring Pt atoms; similar $d-d$ interactions are reported for the $\mathrm{Au}_{2} \mathrm{Al}, \mathrm{AuAl}$, and $\mathrm{AuAl}_{2}$ phases in $\mathrm{Au}-\mathrm{Al}$ alloys [52-54]. Analogous to $\mathrm{Au}-\mathrm{Al}$ compounds of increasing $\mathrm{Au}$ content, several trends are observed for increasingly Ptrich Pt-Si thin films: an increase of intensity and broadening of $d$ bands, due to a greater $d-$ $d$ interaction between neighboring Pt lattice sites, and an increase in intensity of the $5 d-3 p$ antibonding band (peak iii), accompanied by a shift of this peak, and the $5 d-3 p$ bonding peak (peak ii), toward Fermi level. 
Peak iv is situated at the bottom of the PtSi VB. Franco and Bentmann have both shown that rather than consisting of pure Si $3 s$ orbitals, the Pt $5 d$ states contribute almost an equal amount to this peak. As predicted by the calculated PDOS of PtSi and $\mathrm{Pt}_{2} \mathrm{Si}$, peak iv moves to a greater $\mathrm{BE}$ for $\mathrm{Pt}_{2} \mathrm{Si}$ (ig. 3); this peak further shifts upward in $\mathrm{BE}$ for the $\mathrm{Pt}_{3} \mathrm{Si}$ phase. The Si CL transitions exhibit $0.0 \mathrm{eV}$ of shifting in BE between any of the three silicides, however VB peak iv shifts a total of $1.0 \mathrm{eV}$ between PtSi and Pt 3 Si. This is contrary to what would be expected if the Si 3s orbitals are instead spatially localized and, like CL orbitals, shift only due to potential energy effects involved in Pt-Si charge transfer. The fact that this peak shifts unlike the Si CLs and away from the main Pt $5 d$ manifold is supporting evidence for a Pt-Si DOS model in which Pt $5 d$ orbitals extend throughout the VB and the Si $3 s$ states play a role in bonding.

\subsection{Phase identification}

For co-evaporated Pt-Si films with nominal Pt:Si ratios of 1:1, 2:1, and 3:1 (i.e., $X_{\mathrm{Si}}=0.50$, 0.33, 0.25), phases of $\mathrm{PtSi}, \mathrm{Pt}_{2} \mathrm{Si}$, and $\mathrm{Pt}_{3} \mathrm{Si}$ respectively form upon deposition at $400{ }^{\circ} \mathrm{C}$, according to X-ray diffraction (XRD) (Fig 4). The compositional $\left(X_{\mathrm{si}}\right)$ ranges over which a particular Pt-Si phase exists is evident in Fig. $\mathbf{5}$, where the phases identified by XRD are plotted versus film compositions calculated from XPS. (The electrical conductivity data included in $\underline{\text { Fig. } \mathbf{5}}$ are discussed in Section 3.4.) As shown in $\underline{\mathbf{F i g} . \mathbf{5}}$, films deviating \pm 5 at. $\%$ Si from $\mathrm{PtSi}, \mathrm{Pt}_{2} \mathrm{Si}$, and $\mathrm{Pt}_{3} \mathrm{Si}$ stoichiometries still exhibit single-phase silicide XRD spectra (hereafter referred to as "single-phase" films), like those displayed in Fig. $\mathbf{4}$, and for films exceeding these compositional ranges, a solid-solid mixture of two contiguous phases was observed in the XRD pattern. Pt-Si co-evaporation with very low Si content $\left(X_{\mathrm{Si}}<0.16\right)$ 
yields films with Pt grains coexisting with finely dispersed $\mathrm{Pt}_{3} \mathrm{Si}$ nanocrystallites. Mixed films that contain $\mathrm{Pt}_{3} \mathrm{Si}+\mathrm{Pt}_{2} \mathrm{Si}$ phases form over a very narrow range, as seen in $\underline{\mathbf{F i g} . \mathbf{5}}$; the formation enthalpies for these two phases (-12.3 and $-14.0 \mathrm{kcal} / \mathrm{mol}$, respectively [55]) appear to advocate the growth of mixed films in this compositional range.

No majority-silicon phases (e.g., $\mathrm{Pt}_{2} \mathrm{Si}_{3}, \mathrm{Pt}_{4} \mathrm{Si}$ ) ) were observed under any growth conditions, indicating that the elevated deposition temperature $\left(400^{\circ} \mathrm{C}\right)$ and relatively low total deposition rate $(0.5 \AA / \mathrm{s})$ are sufficient to prevent the nucleation of such metastable phases, which have elsewhere been induced via post-deposition laser irradiation [56] and ionbeam mixing [57-61]. For films deposited with $X_{\mathrm{Si}}>0.50$, the excess $\mathrm{Si}$ (not bound in PtSi) was found to be amorphous. The growth of amorphous $\mathrm{Si}(\mathrm{a}-\mathrm{Si})$ films via e-beam deposition in vacuum $\left(7 \times 10^{-4} \mathrm{~Pa}\right)$ has been demonstrated by Fang et al. [62], and $520^{\circ} \mathrm{C}$ was found to be the critical temperature below which fully amorphous films form on alumina substrates.

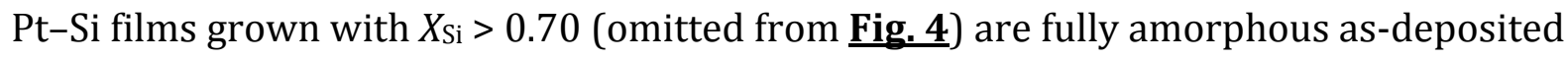
with only a very broad peak extended over Bragg angles $2 \theta=15-35^{\circ}$.

Co-evaporated Pt-Si films with $X_{\mathrm{Si}}<0.65$ all exhibit polycrystalline XRD patterns with slightly preferred textures, as shown in Fig. 4 . The expected cubic-Pt, monoclinic- $\mathrm{Pt}_{3} \mathrm{Si}$, tetragonal-Pt $2 \mathrm{Si}$, and orthorhombic-PtSi phases were observed [63-66], and Scherrer analysis of several XRD peaks for each phase indicates that all Pt-Si film types have a nominal crystallite grain size of $15-30 \mathrm{~nm}$ perpendicular to the film, meaning that on average 7-13 crystalline grains make up the $200 \mathrm{~nm}$ film thickness.

For mixed, Pt $+\mathrm{Pt}_{3} \mathrm{Si}$ films with overall compositions of $X_{\mathrm{Si}}=0.10$ to $0.15,40-60 \%$ of the film is a $\mathrm{Pt}_{3} \mathrm{Si}$ phase, and in this case the Pt grains become less (111) textured than a pure 
Pt film and are more evenly distributed among (111), (200), and (311) orientations. For the stoichiometric Pt ${ }_{3} \mathrm{Si}$ film composition, a small amount (ca. 5\%) of $\beta \mathrm{Pt}_{3} \mathrm{Si}$ is present (Fig. 4), which is the high-temperature, orthorhombic polymorph [67] of the Pt3Si structure. The Pt-rich side of the Pt-Si binary phase diagram has undergone several revisions in recent decades and is still under some dispute [7]; one result of these revisions is that the polymorphic transition temperature for $\alpha \mathrm{Pt}_{3} \mathrm{Si} \rightarrow \beta \mathrm{Pt}_{3} \mathrm{Si}$, which was long reported as $360^{\circ} \mathrm{C}$ [11], has recently been reported as $440^{\circ} \mathrm{C}[\mathbf{7 , 8}]$. The presence of the secondary phase, $\beta \mathrm{Pt}_{3} \mathrm{Si}$, is observed here for depositions performed with a $400 \pm 10^{\circ} \mathrm{C}$ substrate temperature.

\subsection{Film morphology}

Scanning electron microscopy (SEM) was used to study film nanostructure, including morphological grain size and heterogeneity. Figure $\mathbf{6}$ presents plan-view images from asdeposited films of stoichiometric $\mathrm{Pt}_{3} \mathrm{Si}, \mathrm{Pt}_{2} \mathrm{Si}$, and PtSi phases, as well as two dual-phase films: a Pt 2 Si-PtSi film $\left(X_{\mathrm{Si}}=0.39\right)$ and a Si-rich PtSi phase $\left(X_{\mathrm{Si}}=0.64\right)$. For a single-phase PtSi film ( $\underline{\text { Fig. 6d) }}$, the grains are about 3-5 times larger in diameter compared to the

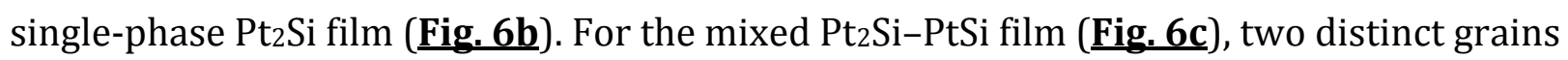
types are evident, which are similar to those found in the $\mathrm{Pt}_{2} \mathrm{Si}$ and PtSi films; EDS measurements confirmed that the two different grain types are in fact those of $\mathrm{Pt}_{2} \mathrm{Si}$ and PtSi.

The melting-point of $\mathrm{Pt}_{3} \mathrm{Si}$ is lower than those for the other two silicides $[\mathbf{7 , 8}]$, which may be the cause of the morphology exhibited by single-phase $\mathrm{Pt}_{3} \mathrm{Si}$ films (Fig. 6a) that is quite dissimilar to those of single-phase $\mathrm{Pt}_{2} \mathrm{Si}$ and PtSi films. We speculate that the lateral non- 
uniformity of $\mathrm{Pt}_{3} \mathrm{Si}$ grains is the result of an Ostwald ripening-like mechanism between neighboring grains during film growth. It is also interesting to note the presence of 5-25 $\mathrm{nm}$ precipitates that decorate the $\mathrm{Pt}_{3} \mathrm{Si}$ film surface. These particulates are identified by EDS and grazing-incidence XRD (GIXRD) as c-Pt nanoparticles and are observed to accumulate only at the growth surface and not beneath. Studies are underway to further probe the existence of these nanoparticles and the early stages of $\mathrm{Pt}_{3} \mathrm{Si}$ grain ripening for other film thicknesses and deposition temperatures.

As observed in Fig. 6e, excess $\mathrm{Si}$ in the $X_{\mathrm{Si}}=0.64$ film appears to form an amorphous-Si matrix that coexists with crystalline PtSi grains. This amorphous phase was confirmed by EDS and CL-XPS to be pure Si and contain no significant amount of oxygen. Previous reports discuss similar accumulation of excess $\mathrm{Si}$ at the surfaces as well as at grain boundaries of Si-rich metal silicide films grown by co-sputtering [68-71].

\subsection{Electrical conductivity}

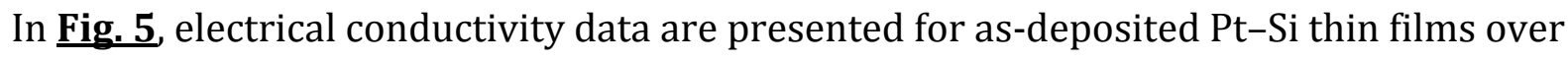
the compositional range $0.00 \leqslant X_{\mathrm{Si}} \leqslant 0.77$. Electrical resistance in thin films arises from several simultaneously operative electron scattering mechanisms, including background scattering within a single crystal grain (due to phonons and point defects) as well as scattering at the crystalline and morphological grain boundaries and external surfaces $[72,73]$. As a result, lower conductivity values are often found for thin films compared to bulk systems. In addition to defect and grain boundary scattering, excess a-Si that can collect in grain boundaries behaves like a capacitive dielectric in Si-rich silicides, increasing the boundary potentials, and thereby greatly decreasing film conductivity [68-71]. This 
mechanism might explain the poor conductivity observed for Si-rich films $\left(X_{\mathrm{Si}}>0.60\right)$, like that depicted in Fig. 6e and discussed in Section 3.3.

The electrical conductivities of the Pt silicide phases have values within a factor of two and are altogether two to three times less than that for films of pure Pt. As shown in Fig. $\mathbf{5}$, stoichiometric $\mathrm{Pt}_{3} \mathrm{Si}, \mathrm{Pt}{ }_{2} \mathrm{Si}$, and PtSi films have room-temperature conductivities of $0.74 \pm$ $0.23 \mathrm{MS} / \mathrm{m}, 1.72 \pm 0.43 \mathrm{MS} / \mathrm{m}$, and $1.02 \pm 0.48 \mathrm{MS} / \mathrm{m}$, respectively. The values for $\mathrm{Pt}_{2} \mathrm{Si}$ and PtSi are roughly half of those for $\mathrm{Pt}_{2} \mathrm{Si}$ and $\mathrm{PtSi}$ films formed by solid-state reaction [6], which generally yields larger grain sizes compared to co-deposition [29]. On the other hand, the values are quite consistent with the conductivities of annealed Pt silicide films grown by co-sputtering [21].

The prominence of metal silicides in microelectronics has resulted in the prevalent use of solid-state reactions between metal films and Si substrates for silicide formation. As a result, there are few reports of synthesizing large regions of the $\mathrm{Pt}_{3} \mathrm{Si}$ phase and reports on its electronic properties are accordingly scarce. Streller et al. $[\mathbf{7 4 , 3 6 ]}$ recently demonstrated that by replacing single crystalline (sc-) or polycrystalline (poly-) Si with a sputtered amorphous Si precursor film, solid-state silicide reaction of a bilayer of a-Si/Pt yields mixed-phase, sub-50 nm thick films that predominantly consist of a $\mathrm{Pt}_{3} \mathrm{Si}$ phase . Si and Pt were sequentially sputtered in various Si:Pt thickness ratios onto PELCO $50 \mathrm{~nm}$ silicon nitride $\left(\mathrm{Si}_{3} \mathrm{~N}_{4}\right)$ support TEM grids and annealed to form mixed films either primarily consisting of $\mathrm{Pt}_{3} \mathrm{Si}_{1} \mathrm{Pt}_{2} \mathrm{Si}$, or PtSi via source-limited (i.e., Si-limited) or kinetically limited (i.e., time/temperature-limited at fixed temperature/time) controlled solid-state diffusion. The authors reported that vital to the novel silicide formation sequence was their evidence 
for Si being the diffusing species in Pt/a-Si reactions, unlike solid-state reactions of Pt on sc- or poly-Si substrates, such that $\mathrm{Pt}_{3} \mathrm{Si}$ precedes the familiar formation series of $\mathrm{Pt}_{2} \mathrm{Si}$ followed by PtSi. By conductive atomic force microscopy (C-AFM) using a Pt sputter-coated tip, they measured the contact resistance of PtSi films and $\mathrm{Pt}_{3} \mathrm{Si}-\mathrm{Pt}{ }_{2} \mathrm{Si}$ mixed films, compared to a Pt film, and determined that the mixed film of Pt-rich silicides is a more metallic contact material (i.e., more similar to Pt) than is PtSi. However, no measurements of electrical sheet conductivity were presented therein.

In the same manner as Streller, Gas et al. [55] demonstrated the growth of primarily- $\mathrm{Pt}_{3} \mathrm{Si}$ films via reacting a source-limited Pt/Si bilayer with a respective thickness ratio of 300 $\mathrm{nm} / 100 \mathrm{~nm}$. The authors, however, made no mention of the crystalline structure or deposition temperature for the evaporated Si precursor. While measuring conductivity in situ while heating up to $650^{\circ} \mathrm{C}$, phases of $\mathrm{Pt}_{2} \mathrm{Si}, \mathrm{Pt}_{12} \mathrm{Si}$, and $\mathrm{Pt} 3 \mathrm{Si}$ were observed to form in sequence and each co-existed with unknown fractions of unreacted Pt, according to XRD and Rutherford backscattering (RBS) analysis. The respective conductivities of the three phases were estimated as $3.5 \mathrm{MS} / \mathrm{m}, 3.1 \mathrm{MS} / \mathrm{m}$, and $1.9 \pm 0.4 \mathrm{MS} / \mathrm{m}$, respectively.

It should be noted that Streller et al. [36] described the PtSi phase as less metallic than a mixture of $\mathrm{Pt}_{2} \mathrm{Si}$ and $\mathrm{Pt}_{3} \mathrm{Si}$ phases, while Gas et al. [55] reported decreasing conductivity values with increasing Pt content, proceeding from $\mathrm{Pt}_{2} \mathrm{Si}$ to $\mathrm{Pt}_{3} \mathrm{Si}$. The data displayed in $\underline{\text { Fig. }}$ $\underline{\mathbf{5}}$ could be consistent with these other reports as it suggests a slight local maximum in electrical conductivity for the $\mathrm{Pt}_{2} \mathrm{Si}$ phase amid the surrounding Pt silicides.

\subsection{Thermal stability}


Co-evaporated Pt-Si films were annealed in vacuum at $1000^{\circ} \mathrm{C}$ in order to explore the thermal stability of their crystalline phase, morphology, and electrical conductivity. In the literature, the onset of agglomeration in $\mathrm{Pt}_{2} \mathrm{Si}$ and $\mathrm{PtSi}$ films has been attributed to the localized melting of Pt-rich regions. According to the bulk phase diagram $[7,8]$, the Pt-Si system consists of three eutectic points, which separate the four congruent melting phases: $\mathrm{Pt}, \mathrm{Si}$, and the two most stable alloys, $\mathrm{Pt} 2 \mathrm{Si}$ and $\mathrm{PtSi}$. The lowest melting temperature in the binary system (ca. $830^{\circ} \mathrm{C}$ ) is found at the Pt-rich eutectic situated at $\mathrm{X}_{\mathrm{Si}}=0.23$. It is assumed that near $830^{\circ} \mathrm{C}$, melting of $\mathrm{Pt}_{3} \mathrm{Si}$-like regions produce spots of enhanced diffusion that serve as activation sites for film dewetting and lead to the decrease in film conductivities reportedly observed around $800-900^{\circ} \mathrm{C}[\mathbf{2 1 , 7 5}]$.

For the case of e-beam co-evaporated Pt-Si films, no local or global agglomeration is observed after annealing at $1000^{\circ} \mathrm{C}$ for $48 \mathrm{~h}$, independent of film composition. Figure 7 displays SEM images, revealing the morphological continuity that is preserved for $\mathrm{Pt}_{3} \mathrm{Si}$, $\mathrm{Pt}_{2} \mathrm{Si}$, and PtSi films after the $48 \mathrm{~h}$ anneal. This stability is radically different than in the case of solid-state reacted Pt silicides [21,75-77] for which agglomeration routinely proceeds within $1 \mathrm{~h}$ at $850^{\circ} \mathrm{C}$ in vacuum or inert atmospheres, causing rapid deterioration of film continuity. Because of the greater thermal stability of the co-evaporated film morphology, the sheet conductivities of these films remain stable to higher temperatures. Upon annealing all three of the co-evaporated silicides, the Scherrer grain sizes and conductivities alike increase only by $20-50 \%$, with no apparent trends, characteristic of a reduction in the density of defects and/or grain boundaries. In the film with $X_{\mathrm{Si}}=0.64$, annealing results in only ca. 5\% grain growth. Nonetheless, its conductivity increases by nearly $300 \%$ to a final value akin to that of the annealed PtSi films that were grown closer 
to stoichiometry and without large quantities of excess a-Si. This result is most likely due to a redistribution of the a-Si away from grain boundaries during annealing and suggests that the a-Si phase indeed collects at grain boundaries, in addition to the exterior film surface, in as-deposited films.

The morphologies of the $\mathrm{Pt}_{2} \mathrm{Si}$ and $\mathrm{PtSi}$ film are largely unaltered as a result of the vacuum annealing at $1000^{\circ} \mathrm{C}$; grain sizes and shapes are nearly identical to those in as-deposited films and little ripening of neighboring grains is observed (Fig. 7). However, the morphology of the $\mathrm{Pt}_{3} \mathrm{Si}$ films, which consisted of a network of interconnected grains in the as-deposited state, becomes much more coarsely grained and noticeably smoother following the $1000{ }^{\circ} \mathrm{C}$ anneal. This morphological change may be the result of resolidification after melting at ca. $900{ }^{\circ} \mathrm{C}[7,8]$, however there is no conclusive proof of this mechanism, and the film remains wetted to the epitaxially polished substrate. Although the $1000^{\circ} \mathrm{C}$ annealing temperature is above the melting point predicted for $\mathrm{Pt}_{3} \mathrm{Si}$ by the bulk Pt-Si phase diagram, the $\mathrm{Pt}_{3} \mathrm{Si}$ films remain primarily monoclinic in phase after cooling, with a slight increase in the amount of the high-temperature, orthorhombic polymorph $\left(\beta \mathrm{Pt}_{3} \mathrm{Si}\right)$. The fact that a crystalline $\mathrm{Pt}_{3} \mathrm{Si}$ phase is fully retained after annealing at $1000^{\circ} \mathrm{C}$ indicates that it, like $\mathrm{Pt}_{2} \mathrm{Si}$ and $\mathrm{PtSi}$, is not a metastable silicide phase as grown by e-beam co-evaporation.

Murarka et al. [21] also observed a Pt ${ }_{3} S i$ phase present in co-deposited Pt-Si films with $X_{\mathrm{Si}}$ $=0.25$, which were grown by room-temperature $\mathrm{dc}$ magnetron sputtering onto poly-Si and $\mathrm{SiO}_{2}$ substrates. However, unlike the co-evaporated films presented here, a transformation of the $\mathrm{Pt}_{3} \mathrm{Si}$ phase to either PtSi or $\mathrm{Pt}_{12} \mathrm{Si}_{5}$ phases was observed (for films grown on poly-Si 
and $\mathrm{SiO}_{2}$, respectively) when these films were annealed at $400-900{ }^{\circ} \mathrm{C}$ in a forming gas mixture.

Co-evaporated, single-phase $\mathrm{Pt}_{3} \mathrm{Si}$ films remain morphologically stable for at least $48 \mathrm{~h}$ at $1000^{\circ} \mathrm{C}$, which is important to note considering that regions of a $\mathrm{Pt}_{3} \mathrm{Si}$-like composition, present in as-deposited PtSi films as a result of film heterogeneities and composition fluctuations, are believed to be the cause of the rapid agglomeration observed for solidstate reacted films of PtSi above $850^{\circ} \mathrm{C}$, as mentioned above. We expect that this superior thermodynamic stability and the suppression of agglomeration effects are due to the smooth and finely grained as-deposited morphologies of e-beam co-evaporated Pt silicides, which hinder the long-range mass transport necessary for hole growth, as predicted by thermodynamic modeling [28].

\section{Conclusions}

Pt-Si thin films with Si atomic fractions ranging from $X_{\mathrm{Si}}=0.00-0.77$ were grown at $400{ }^{\circ} \mathrm{C}$ onto r-sapphire substrates by UHV e-beam co-evaporation from independently controlled Pt and Si evaporant sources. As-deposited films and films annealed up to $1000^{\circ} \mathrm{C}$ in vacuum were characterized with the purpose of exploring their phase, morphological, and electrical stability at temperatures where solid-state reacted Pt-Si films routinely agglomerate. The ability to grow single-phase $\mathrm{Pt}_{3} \mathrm{Si}$ films via e-beam co-evaporation is demonstrated and, depending on the film composition, crystalline phases of cubic-Pt, monoclinic-Pt ${ }_{3} \mathrm{Si}$, tetragonal-Pt $2 \mathrm{Si}$, and orthorhombic-PtSi were observed to form. Films with excess $\mathrm{Si}$ in the range of $X_{\mathrm{Si}}=0.50-0.65$ contain an amorphous-Si phase that collects at the film surface and in grain boundaries, whereas films with $X_{\mathrm{Si}}>0.65$ are fully amorphous. 
Valence band XPS spectra from $\mathrm{Pt}, \mathrm{Pt}_{2} \mathrm{Si}$, and PtSi phases agree with previous reports and a valence spectrum is presented for the $\mathrm{Pt}_{3} \mathrm{Si}$ phase. These spectra offer experimental support for recently proposed revisions to the standard transition metal-silicon bonding model. Film morphology of co-evaporated Pt silicides is highly dependent upon phase and differs for each of the three silicide phases. As-deposited films, nominally $200 \mathrm{~nm}$ thick, are electrically conductive in the range of $0.1-4.0 \times 10^{6} \mathrm{~S} / \mathrm{m}$ and conductivities measured from single-phase Pt, $\mathrm{Pt}_{3} \mathrm{Si}, \mathrm{Pt}_{2} \mathrm{Si}$, and PtSi films are $3.66 \pm 0.20 \mathrm{MS} / \mathrm{m}, 0.74 \pm 0.23 \mathrm{MS} / \mathrm{m}, 1.72 \pm$ $0.43 \mathrm{MS} / \mathrm{m}$, and $1.02 \pm 0.48 \mathrm{MS} / \mathrm{m}$, respectively, suggesting a local maximum in conductivity for the $\mathrm{Pt}_{2} \mathrm{Si}$ phase among the Pt silicides, in agreement with other reports. Electrical conductivities slightly improve after vacuum annealing for $48 \mathrm{~h}$ at $1000{ }^{\circ} \mathrm{C}$ and all films, stoichiometric and otherwise, remain morphologically stable from agglomeration during the anneal. Grain coarsening is observed for $\mathrm{Pt}_{3} \mathrm{Si}$ films as a result of vacuum annealing, though the morphologies of $\mathrm{Pt}_{2} \mathrm{Si}$ and PtSi films are largely unaltered. Additionally, $\mathrm{Pt}_{3} \mathrm{Si}$ films retain their as-deposited silicide phase after annealing at temperatures beyond its near-eutectic bulk melting point, indicating that the $\mathrm{Pt}_{3} \mathrm{Si}$ phase is not metastable as grown by e-beam co-evaporation. Because of the superior thermal stability of the co-evaporated film morphology, the sheet conductivities of co-evaporated films remain stable to higher temperatures, offering the opportunity to use them in hightemperature electronic applications where enhanced film stability is desired.

\section{Acknowledgments}


This work was funded by the National Science Foundation (NSF) under Sustainable

Chemistry, Engineering \& Materials (SusChEM) grant \#1309983. The authors would like to thank Drs. George Bernhardt, Robert Meulenberg, and David Frankel for their valuable discussions and insight.

\section{References}

[1] M.K. Niranjan, Theoretical investigation of contact materials for emerging electronic and spintronic devices [dissertation], The University of Texas at Austin (2007).

[2] S.P. Murarka, Silicide thin films and their applications in microelectronics, Intermet. 3 (1995) 173-186.

[3] D.-X. Xu, J. P. McCaffrey, S.R. Das, G.C. Aers, L.E. Erickson, Electrical and structural properties of PtSi films in deep submicron lines, Appl. Phys. Lett. 68 (1996) 3588-3590.

[4] D.-X. Xu, S.R. Das, L. Erickson, A. Naem, Thermal Stability of Nickel Silicide Films, MRS Symp. Proc. 391 (1995) 223-228.

[5] W.J. Strydom, J.C. Lombaard, R. Pretorius, Thermal oxidation of the silicides $\mathrm{CoSi}_{2}, \mathrm{CrSi}_{2}$, NiSi2, PtSi, TiSi2, and $\mathrm{ZrSi}_{2}$, Thin Solid Films 131 (1985) 215-231.

[6] E.G. Colgan, J.P. Gambino, Q.Z. Hong, Formation and stability of silicides on polycrystalline silicon, Mater. Sci. Eng. R16 (1996) 43-96.

[7] H. Okamoto, Pt-Si (Platinum-Silicon), J. Phase Equilib. Diff. 32 (2011) 394-395.

[8] L.L. Xu, J. Wang, H.S. Liu, Z.P. Jin, Thermodynamic assessment of the Pt-Si binary system, Comp. Coupling Phase Diagr. Thermochem. 32 (2008) 101-105.

[9] H. Okamoto, Pt-Si (Platinum-Silicon), J. Phase Equilib. 16 (1995) 286-287.

[10] R. Massara, P. Feschotte, Le système binaire Pt-Si, J. Alloy Compd. 201 (1993) 223-227.

[11] L.E. Tanner, H. Okamoto, The Pt-Si (Platinum-Silicon) System, J. Phase Equilib. 12 (1991) 571-574.

[12] H. Bentmann, A.A. Demkov, R. Gregory, S. Zollner, Electronic, optical, and surface properties of PtSi thin films, Phys. Rev. B 78 (2008) 205302.

[13] O. Beckstein, J.E. Klepeis, G.L.W. Hart, O. Pankratov, First-principles elastic constants and electronic structure of alpha-Pt 2 Si and PtSi, Phys. Rev. B 63 (2001) 134112.

[14] J.E. Klepeis, O. Beckstein, O. Pankratov, G.L.W. Hart, Chemical bonding, elasticity, and valence force field models: A case study for alpha-Pt $2 \mathrm{Si}$ and PtSi, Phys. Rev. B 64 (2001) 155110.

[15] N. Franco, J.E. Klepeis, C. Bostedt, T. van Buuren, C. Heske, O. Pankratov, T.A. Callcott, D.L. Ederer, L.J. Terminello, Experimental and theoretical electronic structure determination for PtSi, Phys. Rev. B 68 (2003) 045116. 
[16] N. Franco, J.E. Klepeis, C. Bostedt, T. van Buuren, C. Heske, O. Pankratov, L.J. Terminello, Valence band study of the PtSi by synchrotron radiation photoelectron spectroscopy, J. Electron Spectrosc. 1191 (2001) 114-116.

[17] H. Koc, E. Deligöz, A.M. Mamedov, The elastic, electronic, and optical properties of PtSi and PtGe compounds, Philos. Mag. 91 (2011) 3093-3107.

[18] M. Eizenberg, H. Foell, K.N. Tu, Shallow silicide contacts formed by using codeposited $\mathrm{Pt}_{2} \mathrm{Si}$ and Pt ${ }_{1.2}$ Si films, Appl. Phys. Lett. 37 (1980) 547-549.

[19] M. Eizenberg, H. Foell, K.N. Tu, Formation of shallow Schottky contacts to Si using Pt-Si and Pd-Si alloy films, J. Appl. Phys. 52 (1981) 861-868.

[20] M. Eizenberg, R. Brener, Auger electron spectroscopy analysis of the contact reaction of PtSi codeposited films and silicon, Thin Solid Films 88 (1982) 41-48.

[21] S.P. Murarka, E. Kinsbron, D.B. Fraser, J.M. Andrews, E.J. Lloyd, High temperature stability of PtSi formed by reaction of metal with silicon or by cosputtering, J. Appl. Phys. 54 (1983) 6943-6951.

[22] T. Stark, H. Grunleitner, M. Hundhausen, L. Ley, Deriving the kinetic parameters for Ptsilicide formation from temperature ramped in situ ellipsometric measurements, Thin Solid Films 358 (2000) 73-79.

[23] G. Larrieu, E. Dubois, X. Wallart, X. Baie, J. Katcki, Formation of platinum-based silicide contacts: Kinetics, stoichiometry, and current drive capabilities, J. Appl. Phys. 94 (2003) 7801-7810.

[24] A.K. Pant, S.P. Murarka, C. Shepard, W. Lanford, Kinetics of platinum silicide formation during rapid thermal processing, J. Appl. Phys. 72 (1992) 1833-1836.

[25] S.R. Das, K. Sheergar, D.-X. Xu, A. Naem, Thickness dependence of the properties and thermal stability of PtSi films, Thin Solid Films 253 (1994) 467-472.

[26] D. Wang, S. Penner, D.S. Su, G. Rupprechter, K. Hayek, R. Schlögl, Silicide formation on a $\mathrm{Pt} / \mathrm{SiO}_{2}$ model catalyst studied by TEM, EELS, and EDXS, J. Catal. 219 (2003) 434-441.

[27] J. Cechal, T. Sikola, A study of the formation and oxidation of PtSi by SR-PES, Surf. Sci. 600 (2006) 4717-4722.

[28] C.V. Thompson, Solid-state dewetting of thin flms, Annu. Rev. Mater. Res. 42 (2012) 399434.

[29] S.P. Murarka, Codeposited silicides in very-large-scale integration, Thin Solid Films (1986) 35-50.

[30] ASTM F390-98, Standard Test Method for Sheet Resistance of Thin Metallic Films With a Collinear Four-Probe Array, ASTM International, West Conshohocken, PA, USA, 1998, http://www.astm.org/DATABASE.CART/HISTORICAL/F390-98R03.htm

[31] Average Matrix Relative Sensitivity Factors (AMRSFs) for X-ray Photoelectron Spectroscopy (XPS), National Physical Laboratory, Teddington, Middlesex, U.K, 2006, http://www.npl.co.uk/science-technology/surface-and-nanoanalysis/services/xps-andaes-average-matrix-relative-sensitivity-factors

[32] J.F Moulder, W.F. Stickle, P.E. Sobol, K.D. Bomben, Handbook of X-ray Photoelectron Spectroscopy: A Reference Book of Standard Spectra for Identification and Interpretation 
of XPS Data, Eden Prairie, MN, Perkin-Elmer Corporation Physical Electronics Division, 1992.

[33] S. Doniach, M. Sunjic, Many-electron singularity in X-ray photoemission and X-ray line spectra from metals, J. Phys. C: Solid State Phys. 3 (1970) 285-291.

[34] S. Hufner, G.K. Wertheim, Core-line asymmetries in the x-ray-photoemission spectra of metals, Phys. Rev. B 11 (1975) 678-683.

[35] N. Fairley, CasaXPS Software Version 2.3.17, United Kingdom, Casa Software Ltd. (2014).

[36] F. Streller, G.E. Wabiszewski, F. Mangolini, G. Feng, R.W. Carpick, Tunable, source-controlled formation of platinum silicides and nanogaps from thin precursor films, Adv. Mater. Interfaces 7 (2014) 1300120.

[37] P.J. Grunthaner, F.J. Grunthaner, A. Madhukar, Chemical bonding and charge redistribution: Valence band and core-level correlations for the $\mathrm{Ni} / \mathrm{Si}, \mathrm{Pd} / \mathrm{Si}$, and Pt/Si systems, J. Vac. Sci. Technol. 20 (1982) 680-683.

[38] J. Battistoni, Platinum complexes of the methyl-esters of dithiocarbazic acid and 3phenyldithiocarbazic acid, J. Chem. Soc.-Dalton 7 (1984) 1293-1299.

[39] S.-E. Karlsson, C.H. Norberg, O. Nilsson, S. Hogberg, A.H. El-Farrash, C. Nordling, K. Siegbahn, Electron binding energies in platinum, Ark. Fys. 38 (1968) 341-349.

[40] J.E. Drawdy, G.B. Hoflund, S.D. Gardner, E. Yngvadottir, D.R. Schryer, Effect of pretreatment on platinized tin oxide catalyst used for low-temperature co-oxidation, Surf. Interface Anal. 16 (1990) 369-374.

[41] M. Alnot, V. Gorodetskii, A. Cassuto, J.J. Ehrhardt, Auger-electron spectroscopy, X-ray photoelectron spectroscopy, work function measurements and photoemission of adsorbed xenon on thin-films of Pt-Re(111) alloys, Thin Solid Films 151 (1987) 251-262.

[42] J. Thiele, N.T. Barrett, R. Belkhou, C. Guillot, H. Koundi, An experimental-study of the growth of $\mathrm{Co} / \mathrm{Pt}(111)$ by core-level photoemission spectroscopy, low-energy-electron diffraction and auger-electron spectroscopy, J. Phys.: Condens. Mat. 6 (1994) 5025-5038.

[43] G.M. Bancroft, I. Adams, L.L. Coatsworth, C.D. Bennewitz, J.D. Brown, W.D. Westwood, ESCA study of sputtered platinum films, Anal. Chem. 47 (1975) 586-588.

[44] T.A. Clarke, I.D. Gay, R. Mason, The valence band of platinum: ESCA studies based on clean (100) and (111) surfaces and their chemisorption of carbon monoxide and other unsaturated molecules, Chem. Phys. Lett. A 27 (1974) 172-174.

[45] S. Kowalczyk, L. Ley, R. Pollak, D.A. Shirley, High-resolution XPS spectra of Ir, Pt and Au valence bands, Phys. Lett. A 41 (1972) 455-456.

[46] H. Hochst, S. Hufner, A. Goldmann, XPS-valence bands of iron, cobalt, palladium and platinum, Phys. Lett. A 57 (1976) 265-266.

[47] G. Rossi, d-metal and f-metal interface formation on silicon, Surf. Sci. Rep. 7 (1987) 1-101.

[48] I. Abbati, L. Braicovich, B. De Michelis, Electronic structure of compounds at platinum silicon (111) interface, Solid State Commun. 37 (1981) 119-122.

[49] G.W. Rubloff, P.S. Ho, Electronic structure at silicide-silicon interfaces, Thin Solid Films 93 (1982) 21-40.

[50] S. Yamauchi, S. Kawamoto, M. Hirai, M. Kusaka, M. Iwami, H. Nakamura, H. Ohshima, T. Hattori, Valence-band density of states of near-noble-metal (Ni, Pd, Pt) monosilicides by using soft-x-ray-emission spectroscopy, Phys. Rev. B 50 (1994) 11564-11569.

[51] Y.M. Yarmoshenko, S.N. Shamin, L.V. Elokhina, V.E. Dolgih, E.Z. Kurmaev, S. Bartkowski, M. Neumann, D.L. Ederer, K.Goranssonk, B. Nolangk, I. Engstromk, Valence band spectra of 4d and 5d silicides, J. Phys.: Condens. Mat. 9 (1997) 9403-9414. 
[52] H. Piao, N.S. McIntyre, High-resolution valence band XPS studies of thin film Au-Al alloys, J. Electron Spectrosc. 119 (2001) 29-33.

[53] H. Piao, N.S. McIntyre, G. Beamson, M.-L. Abel, J.F. Watts, Electronic structures of Au-Al thin-film alloys by high-energy XPS and XANES, J. Electron Spectrosc. 125 (2002) 35-45.

[54] T.K. Sham, M.L. Perlman, R.E. Watson, Electronic behavior in alloys: Gold-non-transitionmetal intermetallics, Phys. Rev. B 19 (1979) 539-545.

[55] P. Gas, J. Tardy, F. LeGoues, F.M. d'Heurle, Electrical measurement of the formation of the platinum-rich metal silicides by metal silicon reaction, Appl. Phys. Lett. 50 (1987) 11351137.

[56] M. von Allmen, S.S. Lau, M. Mäenpää, B.Y. Tsaur, Metastable phases in laser-irradiated PtSi and PdSi thin films, Appl. Phys. Lett. 37 (1980) 84-86.

[57] B.Y. Tsaur, J.W. Mayer, K.N. Tu, Ion-beam induced metastable $\mathrm{Pt}_{2} \mathrm{Si}_{3}$ phase. I. Formation, structure, and properties, J. Appl. Phys. 51 (1980) 5326-5333.

[58] B.Y. Tsaur, J.W. Mayer, J.F. Graczyk, K.N. Tu, Ion-beam-induced metastable $\mathrm{Pt}_{2} \mathrm{Si}_{3}$ phase. II. Kinetics and morphology, J. Appl. Phys. 51 (1980) 5334-5341.

[59] J.F. Graczyk, K.N. Tu, B.Y. Tsaur, J.W. Mayer, Ion-beam-induced metastable $\mathrm{Pt}_{2} \mathrm{Si}_{3}$ phase. III. Structure and diffusion in amorphous $\mathrm{Pt}_{2} \mathrm{Si}_{3}$, J. Appl. Phys. 53 (1982) 6772-6780.

[60] L.S. Hung, Q.Z. Hong, J.W. Mayer, $\mathrm{Pt}_{4} \mathrm{Si}_{9}$ formation by hot substrate ion beam mixing, J. Appl. Phys. 63 (1988) 4651-4654.

[61] L.S. Hung, Q.Z. Hong, J.W. Mayer, Thermal and ion induced silicide formation, Nucl. Instr. Meth. Phys. Res. Sect. B: Beam Interact. Mater. Atoms 37-38 (1989) 414-419.

[62] P.H. Fang, P. Bai, J.H. Kinnier, Z. Huan, C.C. Shubert, Temperature dependent formation of microcrystal and amorphous silicon by vacuum evaporation, J. Non-Cryst. Solids 59-60 (1983) 819-821.

[63] International Centre for Diffraction Data, Powder Diffraction File, Card No. 00-004-0802.

[64] International Centre for Diffraction Data, Powder Diffraction File, Card No. 04-015-7964.

[65] International Centre for Diffraction Data, Powder Diffraction File, Card No. 04-003-0990.

[66] International Centre for Diffraction Data, Powder Diffraction File, Card No. 03-065-7973.

[67] International Centre for Diffraction Data, Powder Diffraction File, Card No. 00-034-0956.

[68] S.P. Murarka, D.B. Fraser, Silicide formation in thin co-sputtered (titanium + silicon) films on polycrystalline silicon and $\mathrm{SiO}_{2}$, J. Appl. Phys., 51 (1980) 350-356.

[69] S.P. Murarka, D.B. Fraser, T.F. Retajcyzk, T.T. Sheng, Co-sputtered molybdenum silicides on thermal $\mathrm{SiO}_{2}$, J. Appl. Phys., 51 (1980) 5380-5385.

[70] H.L. Hoo, J.V. Avins, Compound sputtering cathodes of refractory-metal silicides and thinfilm produced, J. Vac. Sci. Technol. B 3 (1985) 1692-1695.

[71] J.P Gambino, E.G. Colgan, Silicides and ohmic contacts, Mater. Chem. Phys. 52 (1998) 99146.

[72] A.F. Mayadas, M. Shatzkes, Electrical-resistivity model for polycrystalline films: the case of arbitrary reflection at external surfaces, Phys. Rev. B 1 (1970) 1382-1389.

[73] J.W. Tringe, J.D. Plummer, Electrical and structural properties of polycrystalline silicon, J. Appl. Phys. 87 (2000) 7913-7926.

[74] F. Streller, R. Agarwal, F. Mangolini, R.W. Carpick, Novel Metal Silicide Thin Films by Design via Controlled Solid-State Diffusion, Chem. Mater. 27 (2015) 4247-4253.

[75] A.K. Sinha, R.B. Marcus, T.T. Sheng, S.E. Haszko, Thermal stability of thin PtSi films on silicon substrates, Appl. Phys. 43 (1972) 3637-3643. 
[76] K.-R. Lee, I.-P. Lin, H.-T. Chang, S.-W. Lee, Platinum silicide formation on Si1-y $\mathrm{C}_{\mathrm{y}}$ epitaxial layers, J. Alloy Compd. 574 (2013) 415-420.

[77] J.-Y. Tsai, B.-Y. Tsui, M.-C. Chen, High temperature stability of platinum silicide associated with fluorine implantation, J. Appl. Phys. 67 (1990) 3530-3533. 


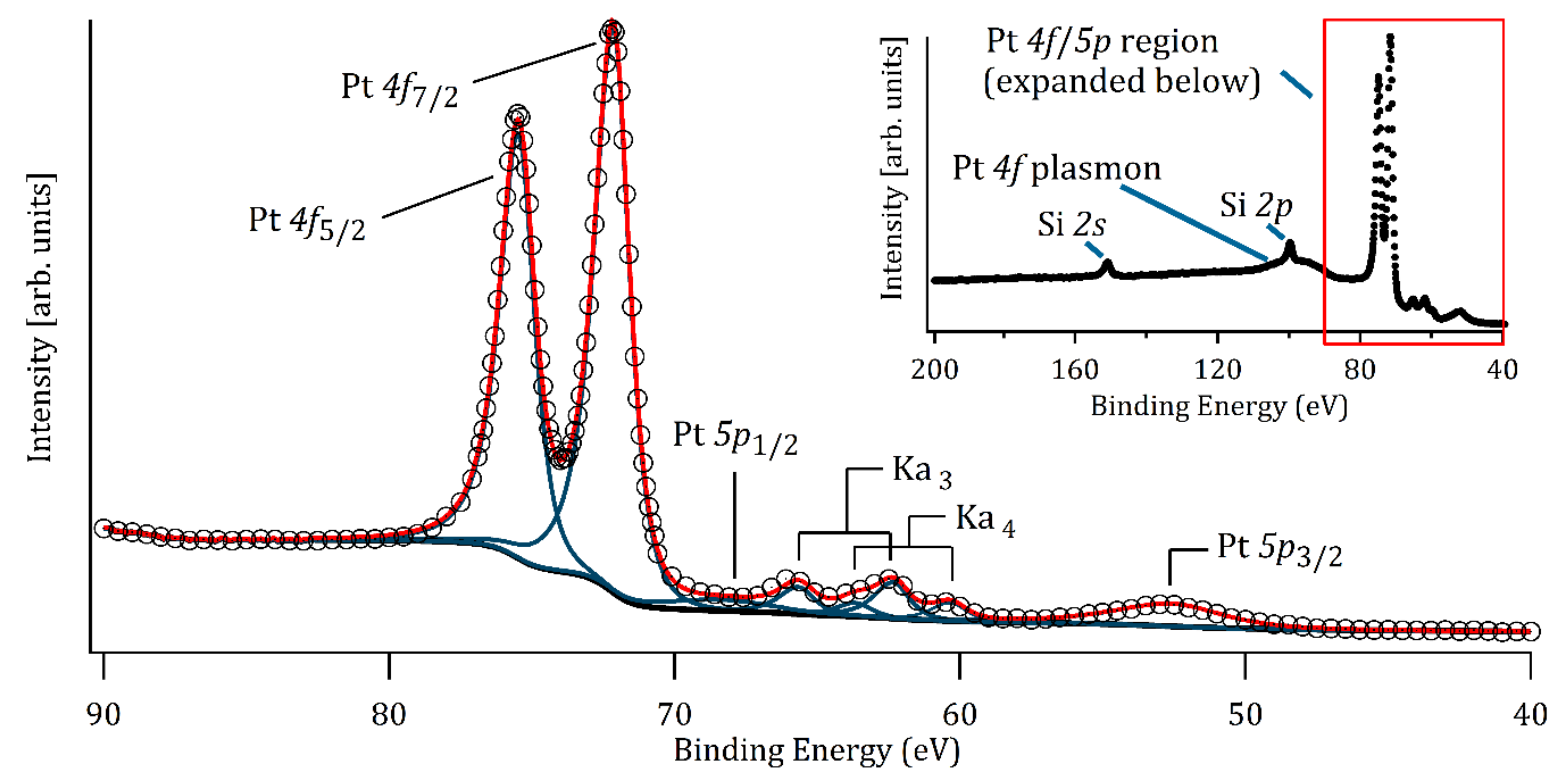

Fig. 1. (Color online) XPS data for a film with $X_{\mathrm{Si}}=0.31$. The survey scan (inset) shows photoemission from several Pt and Si orbitals including Pt $4 f$ and $\mathrm{Si} 2 s$, which are used for Pt:Si quantification $\left(X_{\mathrm{Si}}\right)$. The narrow scan presents the Pt $4 f$ and $5 p$ photopeaks, as well as the $4 f$ satellites, and illustrates the need for individual fitting of overlapping peaks. 


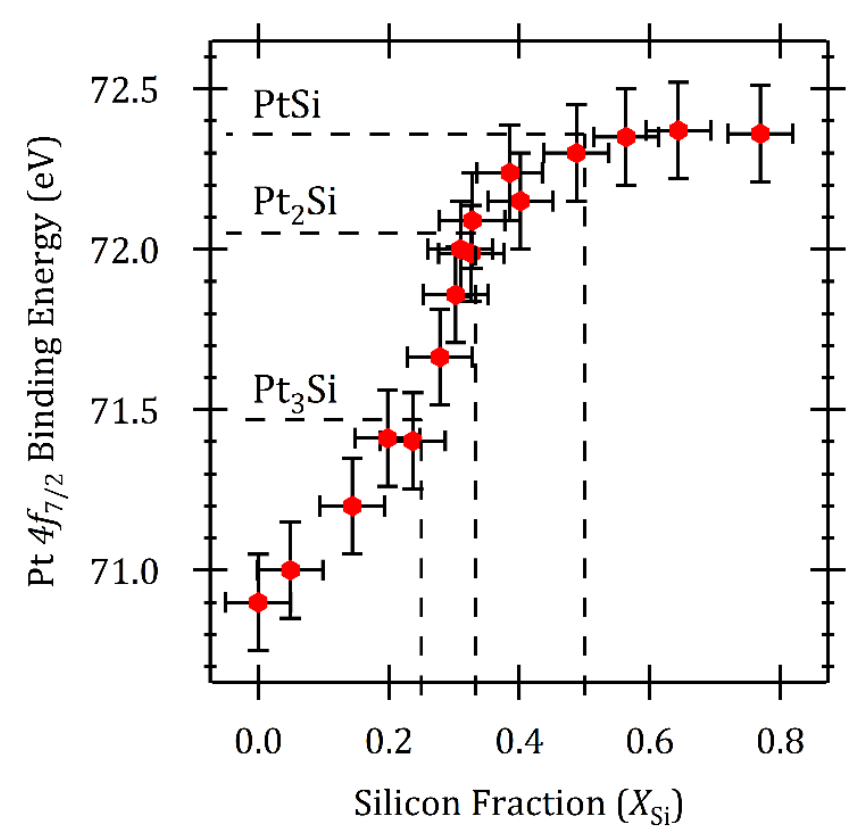

Fig. 2. (Color online) Binding energies of the Pt $4 f_{7 / 2}$ photopeak for Pt-Si films with different compositions $\left(X_{\mathrm{Si}}\right)$. The $4 f_{7 / 2}$ peak shifts to higher binding energy with increased inclusion of Si during film growth. Dotted lines project the $4 f_{7 / 2}$ binding energy associated with $\mathrm{Pt}_{3} \mathrm{Si}_{1} \mathrm{Pt}_{2} \mathrm{Si}$, and $\mathrm{PtSi}$ stoichiometries (i.e., $X_{\mathrm{Si}}=0.25,0.33$, and 0.50 ), measured to be $70.9 \mathrm{eV}$ for pure Pt and $71.5 \mathrm{eV}, 72.1 \mathrm{eV}$, and $72.4 \mathrm{eV}$ for the respective silicides. 
Fryer 27

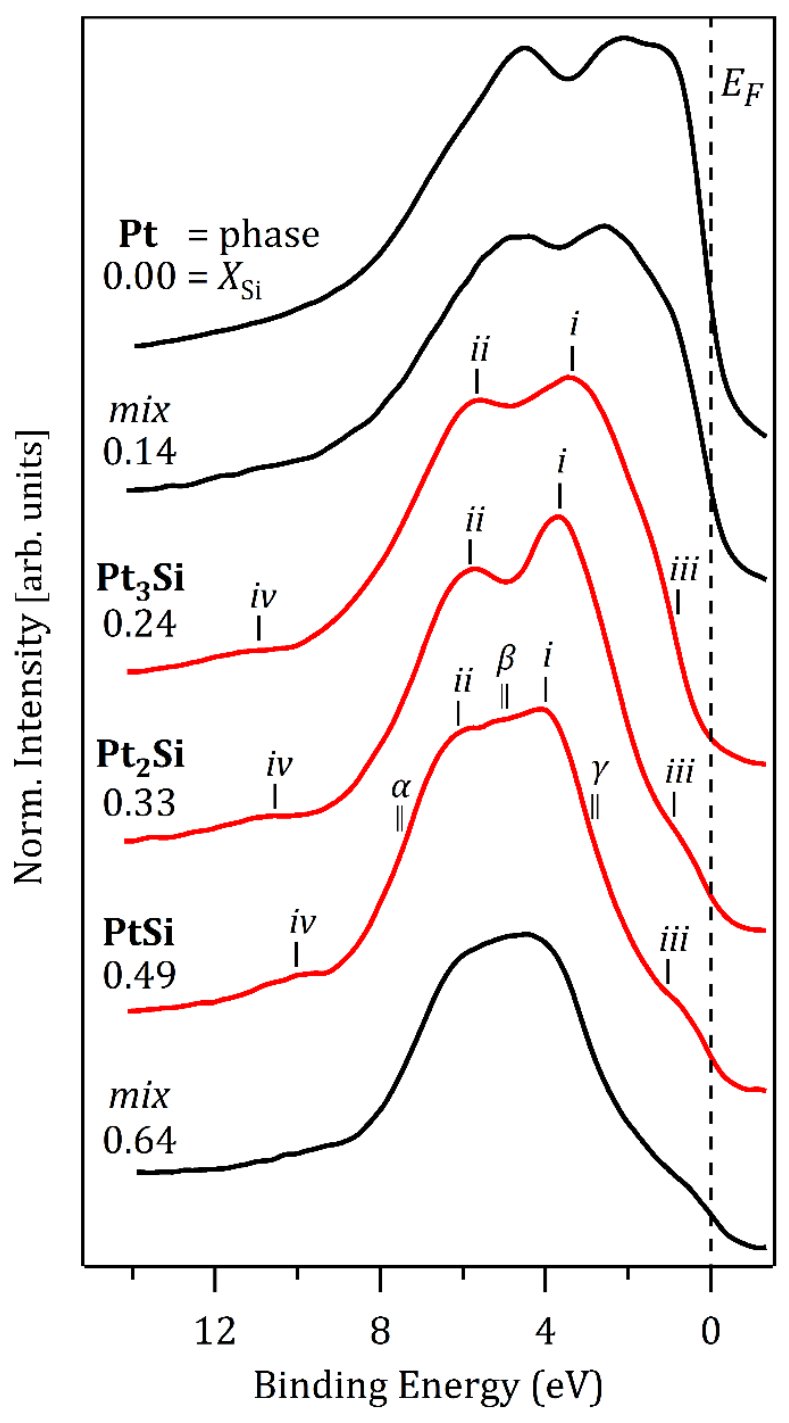

Fig. 3. (Color online) Valence band spectra measured by XPS from as-deposited films comprised of stoichiometric $\mathrm{Pt}_{3} \mathrm{Si}, \mathrm{Pt}_{2} \mathrm{Si}$, and $\mathrm{PtSi}$ (red lines) compounds as well as a $\mathrm{Pt}-\mathrm{Pt}_{3} \mathrm{Si}$ mixed film with $X_{\mathrm{Si}}=0.14$, a PtSi-Si mixed film with $X_{S \mathrm{i}}=0.64$, and a pure Pt film for reference (black lines). Binding energies for all spectra are measured relative to the Fermi level, $E_{F}$. Several spectral features, identified in previous studies (Refs. $[\mathbf{1 5 , 1 6 ] ) , ~ a r e ~ l a b e l e d ~ f o r ~ c o m p a r i s o n . ~ ( S e e ~ t e x t ~ f o r ~ d e t a i l s . ) ~}$ 

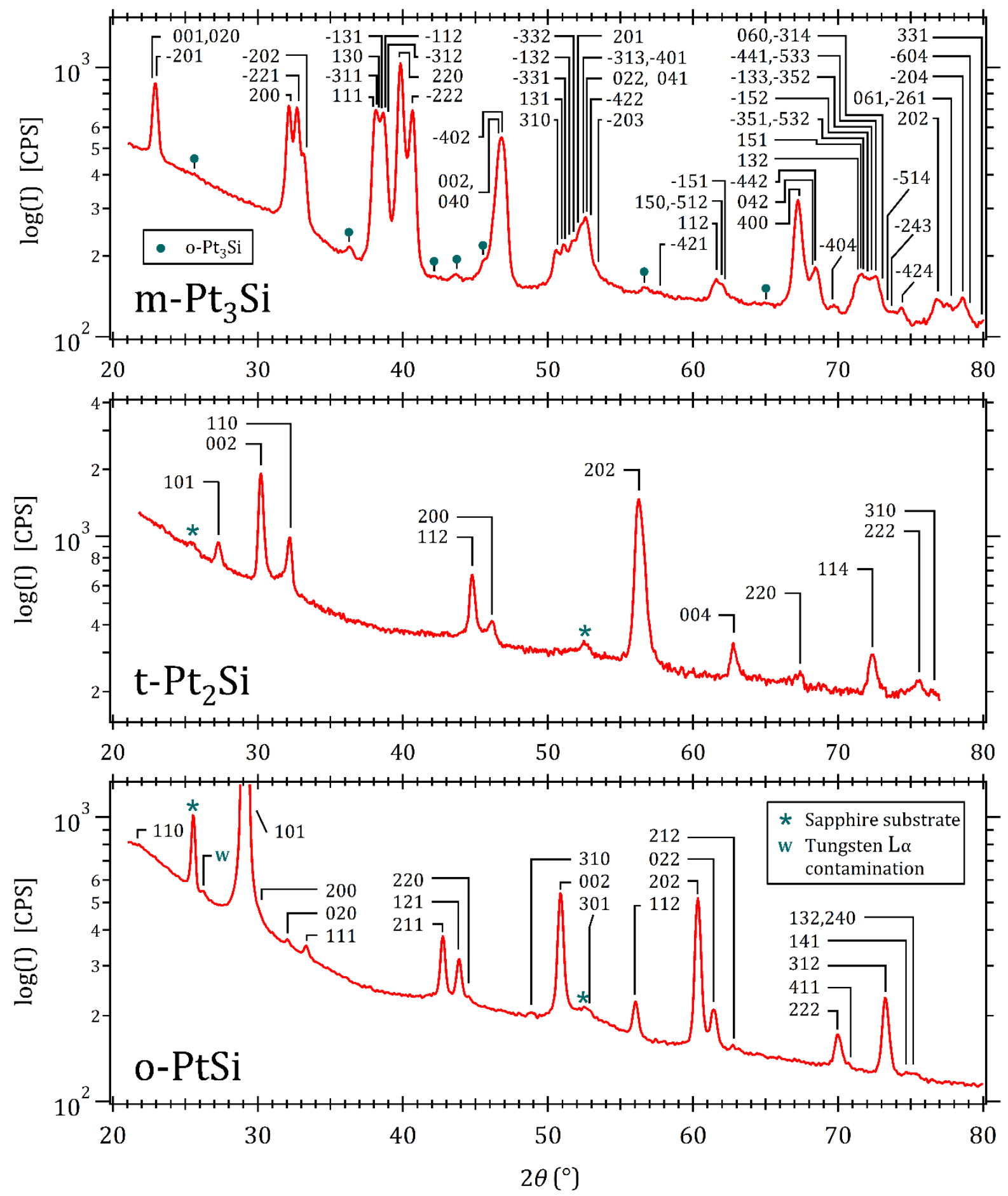

Fig. 4. (Color online) XRD data from as-deposited stoichiometric monoclinic $\mathrm{Pt}_{3} \mathrm{Si}$, tetragonal $\mathrm{Pt}_{2} \mathrm{Si}$, and orthorhombic PtSi films grown at $400^{\circ} \mathrm{C}$. All spectra were measured using a $3^{\circ}$ offset in $\omega$ to avoid the very intense Bragg peaks from the r-sapphire substrate. Miller indices from powder diffraction files are labeled. 


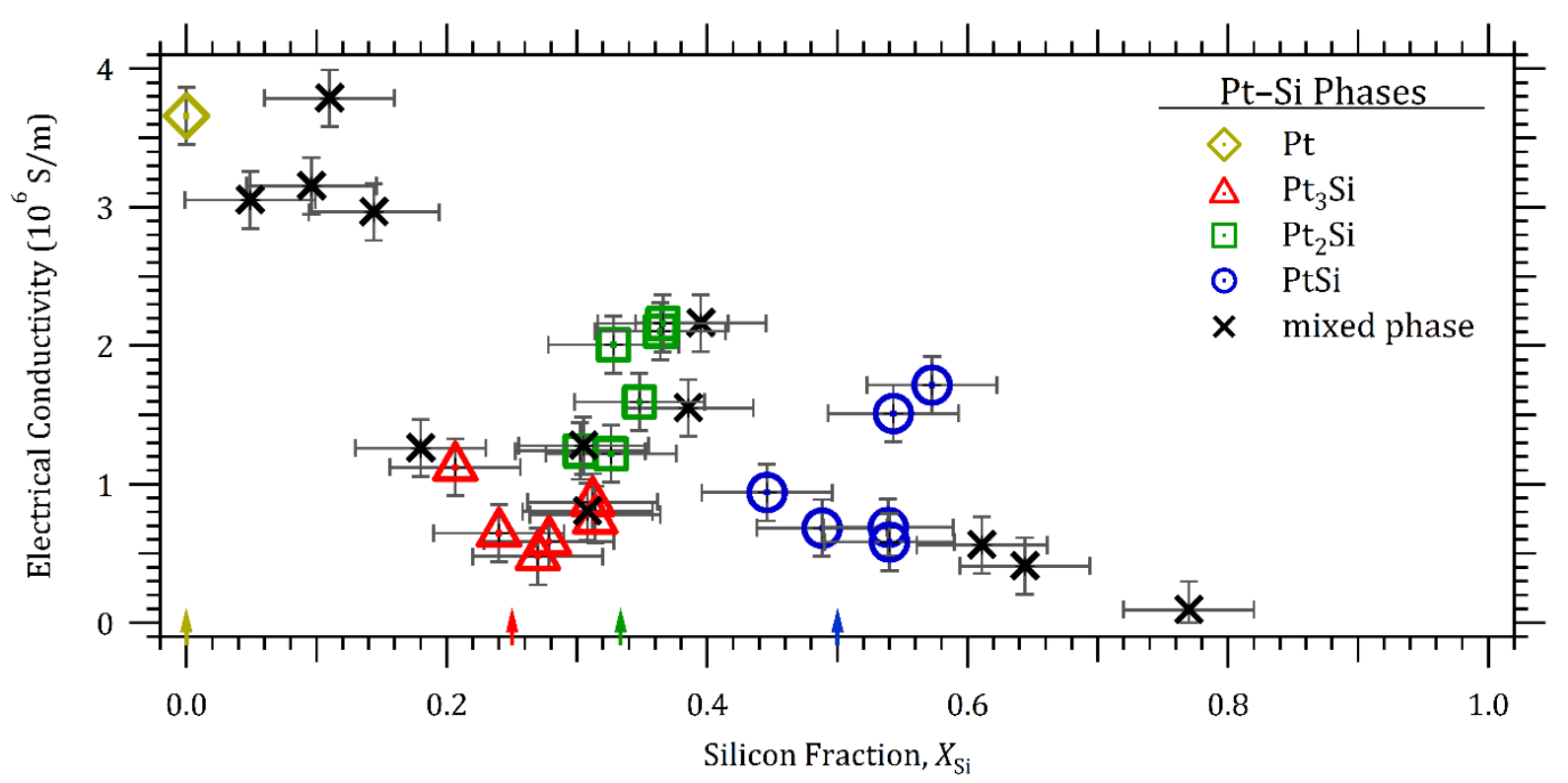

Fig. 5. (Color online) Electrical conductivity data from as-deposited Pt-Si thin films, $0.00 \leqslant X_{\mathrm{Si}} \leqslant 0.77$. Datum markers indicate the Pt-Si phase of the corresponding film, according to XRD. The stoichiometric compositions for each of the four phases (i.e., $X_{\mathrm{Si}}=0.00,0.25,0.33$, and 0.50 ) are denoted on the bottom axis by vertical arrows. 
(a)

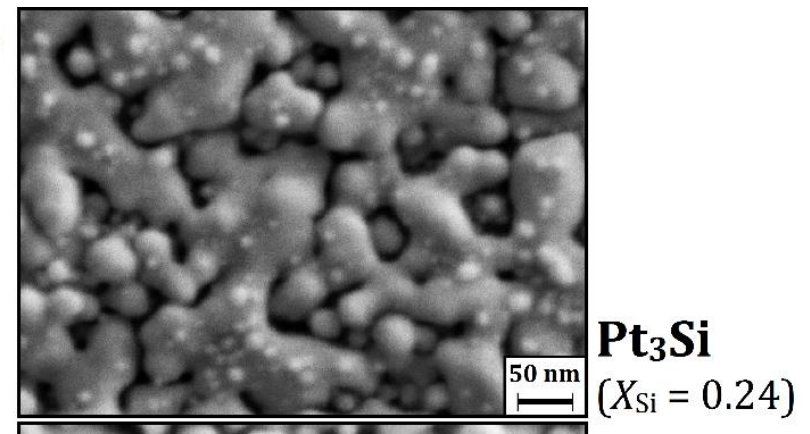

(b)

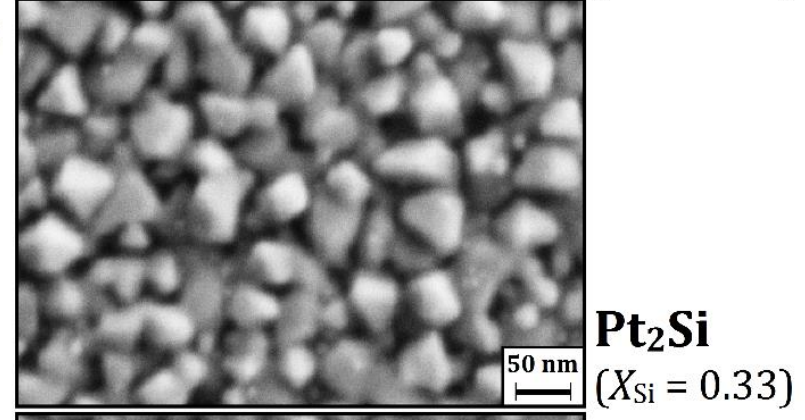

(c)

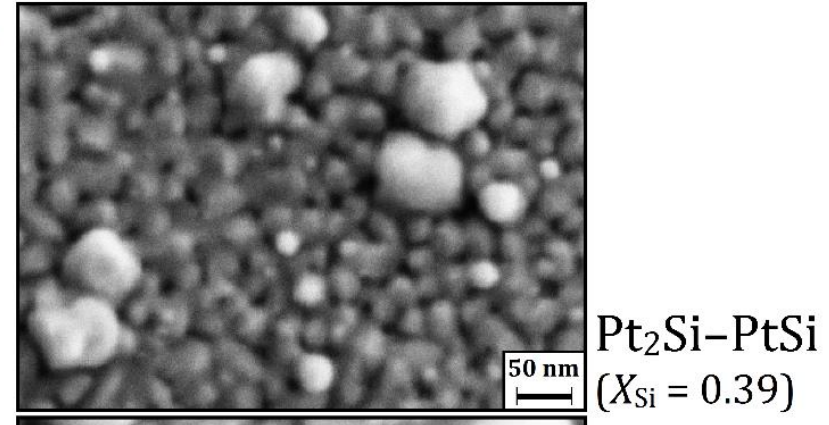

(d)

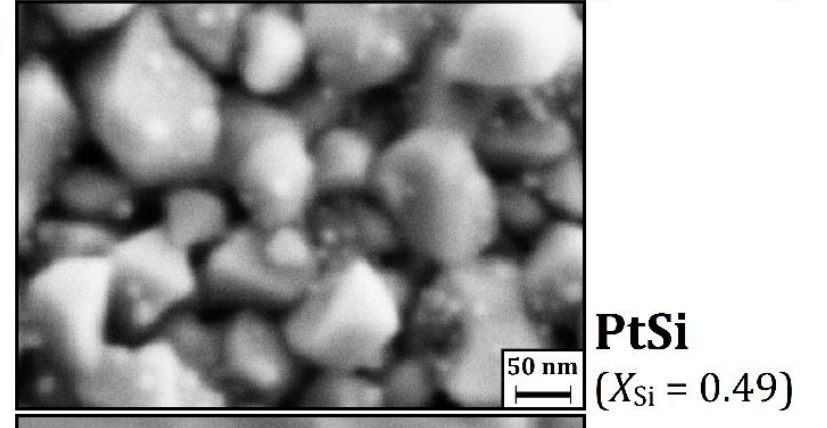

(e)

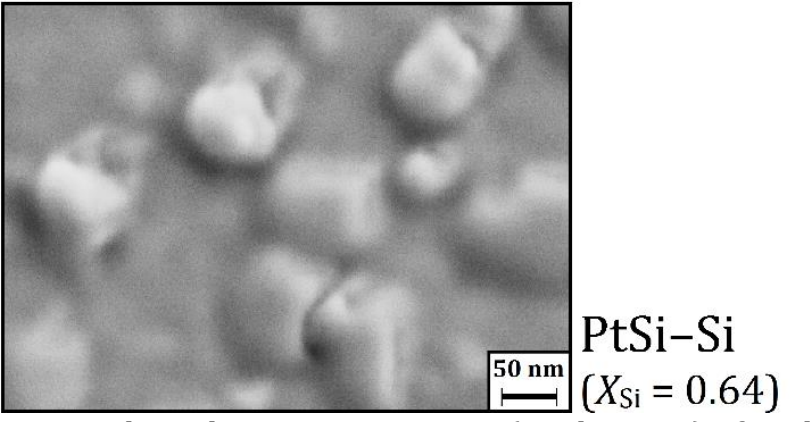

Fig. 6. Secondary electron SEM images (110k× mag.) of as-deposited co-evaporated Pt-Si films grown at 400 ${ }^{\circ} \mathrm{C}$ : (a) $\mathrm{Pt}_{3} \mathrm{Si}$, (b) $\mathrm{Pt}_{2} \mathrm{Si}$, (c) $\mathrm{Pt}_{2} \mathrm{Si}-\mathrm{PtSi}$, (d) PtSi, and (e) PtSi-Si. 


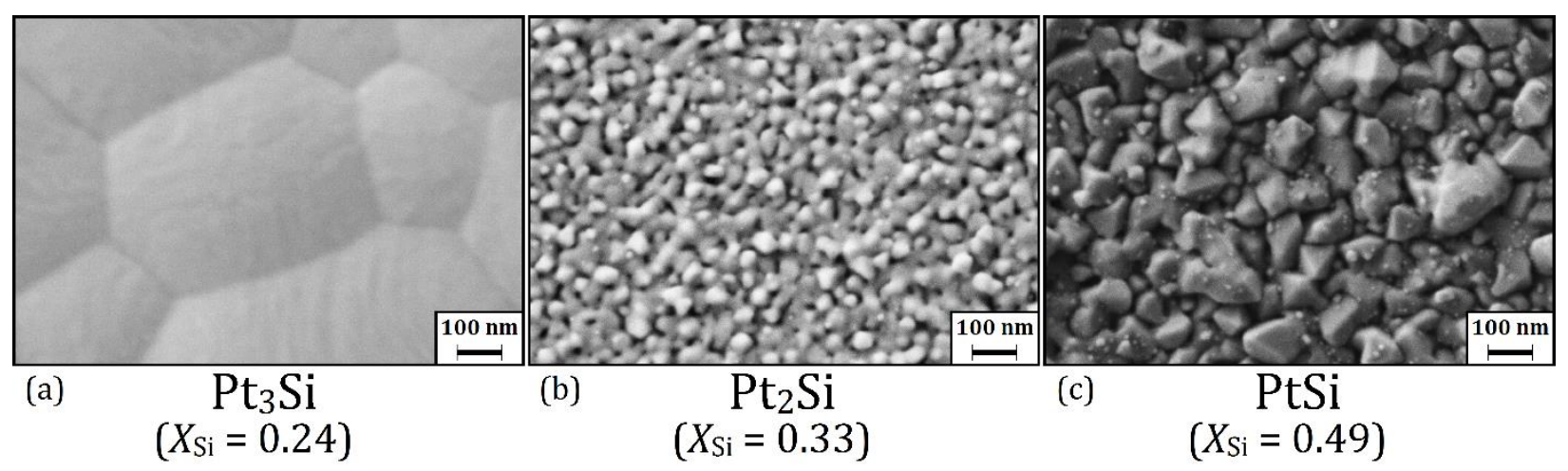

Fig. 7. Secondary electron SEM images (55k× mag.) of stoichiometric (a) $\mathrm{Pt}_{3} \mathrm{Si}$, (b) $\mathrm{Pt}_{2} \mathrm{Si}$, and (c) PtSi films after vacuum annealing at $1000{ }^{\circ} \mathrm{C}$ for $48 \mathrm{~h}$, revealing their preserved morphological continuity during hightemperature processing. 
